Available online at www.iponlinejournal.com

\title{
Prevalence of deleterious oral habits in school going children in Bagalkot region of Karnataka
}

\author{
Bhanuchander Redddy ${ }^{1 *}$, Radha Krishna Gogineni ${ }^{2}$, Sanjay V.Ganeshkar ${ }^{3}$, Kailash L Rathi ${ }^{4}$ \\ ${ }^{1,4}$ MDS, ${ }^{3}$ Professor, ${ }^{4}$ Professor and HOD, Dept. of Orthodontics, PMNM Dental College and Hospital Chennapur Jawahar Nagar \\ Secunderabad, Telangana, India
}

\begin{abstract}
Oral habits, especially if they persist beyond the preschool age, have been implicated as an important environmental etiological factor associated with the development of malocclusion. This study included 2719 children in age group of 11-14 years in school going children in Bagalkot region of Karnataka. This study aims to find the prevalence of habits, malocclusion and their association with the socioeconomic status. The children were examined in the schools and the presence or absence of the thumb sucking, tongue thrusting, nail biting and mouth breathing habit were recorded. Statistical analysis was done using Chi-square test and Fisher's exact test. On clinical examination it shows Prevalence of Habits of $44.9 \%$ with 5.5\% of thumb sucking, $31.7 \%$ tongue thrusting, $7.3 \%$ mouthbreathing and $19.1 \%$ nail biting. It is concluded that the prevalence of malocclusion is high showing $51.1 \%$ and showing no significant difference in rural and urban areas. prevalence of Oral habits is high showing 44.9\%, showing predominantly tongue thrusting and nail biting habits. Oral habits are seen more in rural area compared to the urban area as they belong to different socioeconomic status. Tongue thrusting which is showing statistically significant relationship is more prevalent in rural areas of north Karnataka region of Bagalkot.
\end{abstract}

Keywords: Nail biting, Mouth breathing, Oral habits, Thumb sucking, Tongue thrusting.

\section{Introduction}

Habits are learned patterns of muscle contractions. It is a tendency towards an act that has become a repeated performance, relatively fixed, consistent, easy to perform and almost automatic Oral habits, especially if they persist beyond the preschool age, have been implicated as an important environmental etiological factor with the development of malocclusion ${ }^{1}$.

Head is a composite structure, operationally consisting of numerous autonomous functions such as olfaction, respiration, vision, digestion, speech, audition, equilibration and neural integration. Each function is achieved by a group of soft tissues which are supported by related skeletal elements- concept stated by vanderklauss, the functional matrix hypothesis bones do not grow, but bones are grown. The origin, growth and maintenance of skeletal unit depends almost solely upon its associated functional matrix which is formed by a particular type of soft tissue ${ }^{2}$. Forces from unilateral and habitual behaviours continuously acting on the orofacial region can cause disharmony in these skeletal units, resulting in malocclusion and at times jaw deformities. ${ }^{3}$ Several studies have demonstrated that tongue thrusting, also known as visceral swallowing or infantile swallowing, plays a major role in the aetiology of orofacial deformities.

Calasti, Cohen and Fales $^{1}$ witnessed that higher socioeconomic groups are seen to have considerably more oral habits than those of the middle and lower socioeconomic groups.
Some abnormal oral habits operate at the subconscious level the patient is often unaware of its existence ${ }^{5}$. The data of prevalence and causes of malocclusion can help formulate strategies for prevention, interception, and corrective treatment. In view of financial restraints due to high prices of orthodontic services and lack of public funded dental treatment programs in developing countries, like India, it becomes increasingly important to recognize orthodontic treatment need according to severity and to find modifiable factors that can be targeted to decrease or eliminate malocclusion through preventive and interceptive orthodontics $^{6}$. Oral habits ought to be of primary clinical concern to orthodontists as they may cause malocclusion and interfere with the treatment progress. Generally, habit control should be achieved earlier to correction of the malocclusion in an effort to eliminate any etiologic factors in development and maintenance of the malocclusion. It is well important for the clinician to understand that habit breaking treatment may need prolonged treatment time because habits may have been present for long periods of time and may be associated with underlying psychological problems ${ }^{7}$.

A number of studies have been carried out to determine the prevalence of oral habits in India by Nidhi Pruthi ${ }^{6}$ (25.2\%), Kharbanda $^{8}(25.5 \%)$, Shetty ${ }^{9}$ (29.7\%). The prevalence of oral habits and malocclusion were also determined by Nidhi Pruthi ${ }^{6}(28.8 \%)$, Shetty ${ }^{9}(28.95 \%)$, Sinn J. $\operatorname{Minor}^{10}(23 \%)$.

\footnotetext{
*Corresponding Author: Bhanuchander Redddy, Dept. of Orthodontics, PMNM Dental College and Hospital, Chennapur Jawahar Nagar Secunderabad, Telangana, India

Email: bhanuchander83@gmail.com

http://doi.org/10.18231/j.ijodr.2019.018
} 
However, the prevalence of habits and its association in malocclusion has not, to the best of our knowledge, been yet reported in the district of Bagalkot, Karnataka. This study aims to find the prevalence of habits, malocclusion and their association with the socio economic status.

\section{Materials and Methods}

Random choice of schools in Rural and Urban areas of Karnataka was carried out. The study protocol was reviewed by the Ethical Committee of P.M.N.M. Dental College and Hospital and was granted ethical clearance. A brief about the study was explained to the Principal of the schools and consent was achieved from the Principal to meet the students of the school for the purpose of this study.

A letter to every student explaining the role of the individual within the study (Non clinical and associated Clinical examination) was given to each student among the age group and their consent to be a part of the study was obtained through an attached consent form.

\section{Criteria for collection of data \\ Inclusion criteria}

1. Completed form by parent concerning the child's oral habit.

2. Children with valid consent forms signed by the parents.

\section{Exclusion criteria}

1. Refusal of the consent.

2. Children with general disorders such as neuromuscular and cardiac disorders.

3. Current or previous use of orthodontic appliances.

\section{Method of collection of data}

Two forms were given to each student to be filled:

1. By the parents: This form evaluated the demographic details and socioeconomic status of the individual in which we utilized the Kuppuswamy's socioeconomic scale (updated for the year 2014).

2. Basic questionnaire about the habits

3. Clinical examination of features of various habits and prevailing malocclusion under natural light.

Socioeconomic characteristics were provided via a structured form that was completed by the child's parents or guardians. The questionnaire provided the data on age, gender, education of the head, occupation of the head and family earnings per month in Rs. The socioeconomic status is calculated by adding the totality of all responses and categories them according to Kuppuswamy's socioeconomic scale.

A clinical examination of the individuals who consented to the study, utilising stringent sterilization principles and adequate light, was carried out. Habits will be inspected and identified based on specific tests.

\section{Tongue thrusting}

Tongue depressor or mouth mirror will be placed and the lower lip will be held lightly with thumb and forefingers and the patient will be asked to swallow. Patients with a normal swallow can complete a command swallow of saliva while the lip is so held. Those with a teeth-apart swallow will have the swallow repressed by depression of the lip, since strong mentalis and lip contractions are prerequisite for mandibular stabilization in the teeth apart swallow. ${ }^{11}$

\section{Mouth-breathing}

Is evaluated by placing cotton adjacent to nostrils determining whether the individual is a nasal or oral breather. This is confirmed by examining the dilatation of external nares. Nasal breathers usually demonstrate good reflex control of the alar muscles, which control the dimension and shape of the external nares i.e. they dilate the external nares on inspiration. Mouth-breathers, although they are capable of breathing through the nose, don't change the size or shape of the external nares and lips are parted. ${ }^{11}$

\section{Thumb sucking}

If through the basic questionnaire thumb sucking is disclosed, then the child will be

1. Asked as to which digit was sucked and the way in which it had been sucked.

2. Checked for callus formation, cleaner fingernail or reddish colour or developed rotation which is the most frequent deformation ${ }^{12}$.

3. Duration, frequency and intensity will be determined

\section{Nail biting}

If through the basic questionnaire nail biting is discovered, then the child will demonstrate the nails with short bitten off nails in severed manner.

The IOTN- DHC was used to assess the prevalence of malocclusion in the individuals. This index has gained international acceptance as it is valid, reliable and easy to use. The treatment needs of the patients were categorized as Grade one (no treatment need), Grade two (little treatment need), Grade three (borderline need), and Grade four and five (high treatment need).

IOTN-DHC and Habits ratings were recorded individually by two trained and calibrated examiners. To assess inter-examiner reliability, two hundred children's who were part of this study were selected and re-examined by each examiner at a two to four-week interval after their first examinations. Inter-examiner reliableness for the IOTN-DHC and Habits examiners was almost perfect with kappa $=0.98$. Excellent agreement was found for the interexaminer reliability with Kappa $=0.99$.

1. The data obtained will be subjected to basic statistical analysis and adequate correlation analysis to determine relationships utilizing SPSS software.

2. Chi-square, Fisher exact tests are employed in the study. 


\section{Results}

This study included 2719 children in age group of 11-14 years. Questionnaire was distributed among all children's out of which $152(0.059 \%)$ questionnaires were rejected as it was not filled properly, consents were not obtained from the parents and some of the children's were absent at the time of clinical examination. Thus, 2567 children participate in the study with varied distribution from rural $(41.9 \%)$ and urban $(58.1 \%)$ areas of Karnataka of which $42.3 \%$ children belongs to private school and $57.7 \%$ children belongs to government school showing dissimilar distribution in relation to gender ( $60.3 \%$ boys and $39.7 \%$ girls).

When socioeconomic status of urban and rural was compared using Chi square test, it is showing high statistically significant relationship with $\mathrm{p}<0.001 *$.

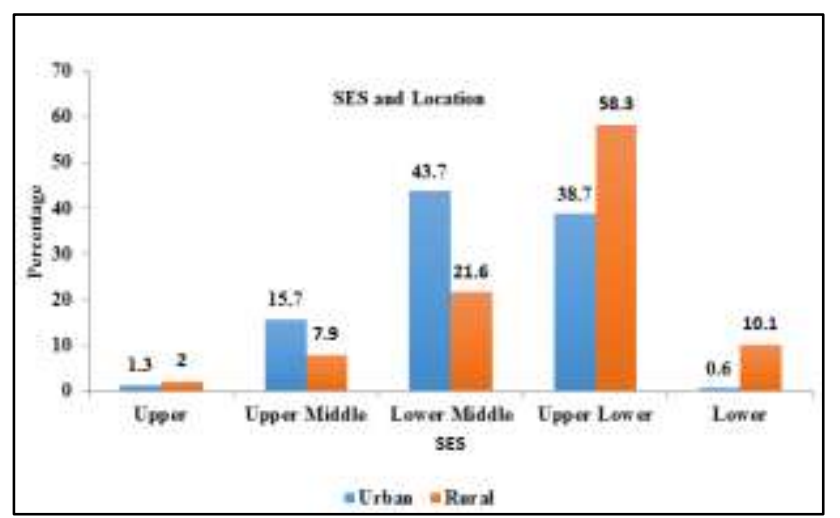

Fig. 1

Socioeconomic status of all children's revealed that most of the children belongs to 'Upper lower' socioeconomic status (38.7\% in urban and $58.3 \%$ in rural) followed by 'Lower middle' $(43.7 \%$ in urban and $21.6 \%$ in rural) with minimum children's belonging to 'Upper' class $(1.3 \%$ in urban and $2 \%$ in rural).

On clinical examination it shows Prevalence of Habits of $44.9 \%$ with $5.5 \%$ of thumb sucking, $31.7 \%$ tongue thrusting, $7.3 \%$ mouthbreathing and $19.1 \%$ nail biting.

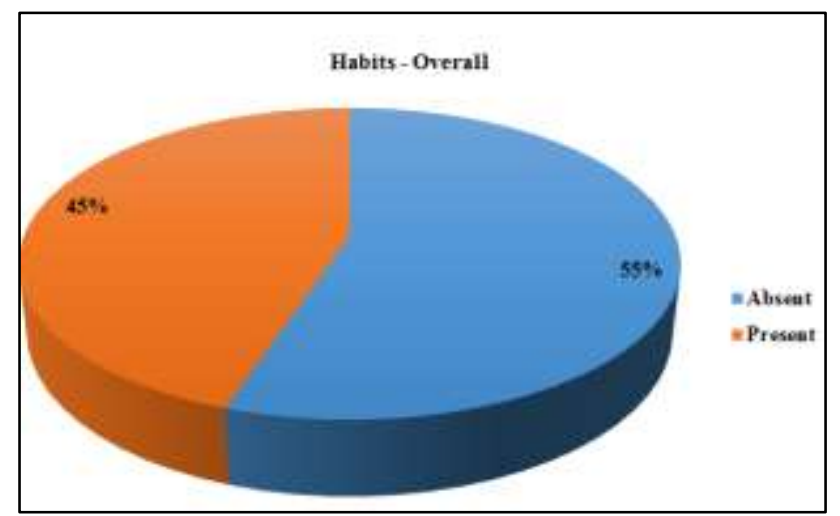

Fig. 2

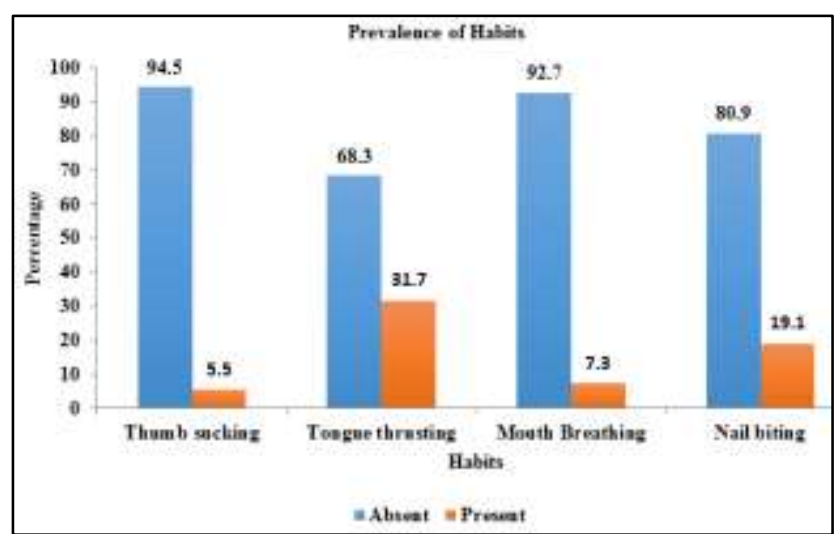

Fig. 3

When socioeconomic status and habits were compared, a statistical significance was observed in relation to tongue thrusting habit $(\mathrm{P}=-0.04 *)$. Tongue thrusting habit was more prevalent in lower class group in rural area according to Kuppuswamy's socioeconomic scale.

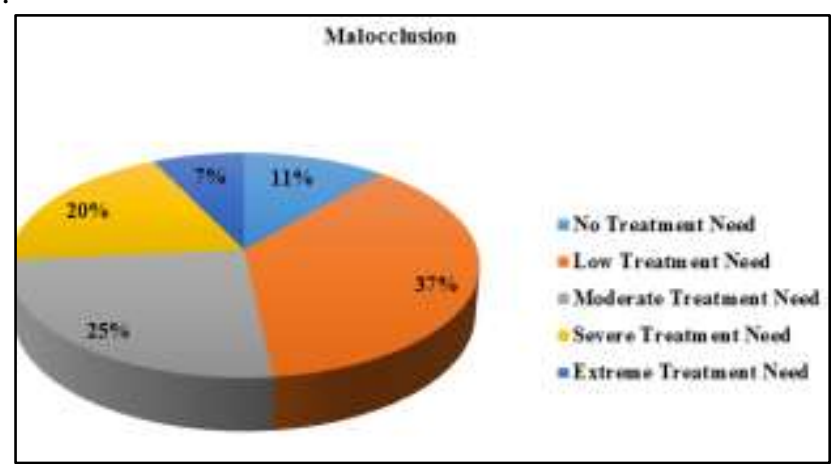

Fig. 4

When clinical examination of the children's was carried out using IOTN-DHC, $11.2 \%$ of children's need no orthodontic treatment, $37 \%$ of them are under mild/little need of treatment category, $25 \%$ of them are under moderate need of orthodontic treatment and $26.5 \%$ of children's are under severe category of orthodontic treatment need. Only the highest scoring trait is used to assess treatment need. So the prevalence of malocclusion in this area is $51.5 \%$

No statistical significant difference was found between various malocclusion parameters among rural and urban areas.

Oral habits when compared in the rural and urban areas there was no significant relationship was found with Thumb Sucking habit and Nail Biting habit, Mouth Breathing habit was significantly related with chi square value of 4.83 (i.e. children with mouth breathing habit were found more in the rural area), Tongue thrusting is highly significant with chi square value of 18.29. Overall Habits are more in rural area compared to urban area showing highly significant relationship with chi square value of 25.06 . 
Table 1

\begin{tabular}{|c|c|c|c|c|c|}
\hline \multicolumn{2}{|c|}{} & Frequency & Percent & Valid Percent & Cumulative Percent \\
\hline \multirow{3}{*}{ Valid } & Urban & 1492 & 58.1 & 58.1 & 58.1 \\
\cline { 2 - 6 } & Rural & 1075 & 41.9 & 41.9 & 100.0 \\
\cline { 2 - 6 } & Total & 2567 & 100.0 & 100.0 & \\
\hline
\end{tabular}

Table 2

\begin{tabular}{|c|c|c|c|c|c|c|}
\hline & \multicolumn{2}{|c|}{ location } & \multirow{2}{*}{ Total } & \multicolumn{2}{|c|}{ Chi square test } \\
\hline & & 1 & 2 & & Chi square value & P-value \\
\hline \multirow{4}{*}{ Thumb sucking } & 0 & 1411 & 1016 & 2427 & \multirow{4}{*}{0.00} & \multirow{4}{*}{$0.99(\mathrm{NS})$} \\
\hline & U & $94.5 \%$ & $94.5 \%$ & $94.5 \%$ & & \\
\hline & 1 & 82 & 59 & 141 & & \\
\hline & 1 & $5.5 \%$ & $5.5 \%$ & $5.5 \%$ & & \\
\hline \multirow{4}{*}{ Mouth Breathing } & 0 & 1370 & 1011 & 2381 & \multirow{4}{*}{4.83} & \multirow{4}{*}{$0.03 *$} \\
\hline & 0 & $91.8 \%$ & $94.0 \%$ & $92.7 \%$ & & \\
\hline & 1 & 123 & 64 & 187 & & \\
\hline & 1 & $8.2 \%$ & $6.0 \%$ & $7.3 \%$ & & \\
\hline \multirow{4}{*}{ Tongue thrusting } & 0 & 970 & 784 & 1754 & \multirow{4}{*}{18.29} & \multirow{4}{*}{$<0.001 *$} \\
\hline & U & $65.0 \%$ & $72.9 \%$ & $68.3 \%$ & & \\
\hline & & 523 & 291 & 814 & & \\
\hline & 1 & $35.0 \%$ & $27.1 \%$ & $31.7 \%$ & & \\
\hline \multirow{4}{*}{ Nail biting } & 0 & 1193 & 885 & 2078 & \multirow{4}{*}{2.37} & \multirow{4}{*}{$0.12(\mathrm{NS})$} \\
\hline & U & $79.9 \%$ & $82.3 \%$ & $80.9 \%$ & & \\
\hline & 1 & 300 & 190 & 490 & & \\
\hline & 1 & $20.1 \%$ & $17.7 \%$ & $19.1 \%$ & & \\
\hline \multirow{4}{*}{ Habit } & 0 & 761 & 655 & 1416 & \multirow{4}{*}{25.06} & \multirow{4}{*}{$<0.001 *$} \\
\hline & 0 & $51.0 \%$ & $60.9 \%$ & $55.1 \%$ & & \\
\hline & 1 & 732 & 420 & 1152 & & \\
\hline & 1 & $49.0 \%$ & $39.1 \%$ & $44.9 \%$ & & \\
\hline \multirow{10}{*}{ Malocclusion } & 1 & 177 & 111 & 288 & \multirow{10}{*}{2.84} & \multirow{10}{*}{$.59(\mathrm{NS})$} \\
\hline & 1 & $11.9 \%$ & $10.3 \%$ & $11.2 \%$ & & \\
\hline & 2 & 562 & 389 & 951 & & \\
\hline & 2 & $37.6 \%$ & $36.2 \%$ & $37.0 \%$ & & \\
\hline & 3 & 371 & 278 & 649 & & \\
\hline & 3 & $24.8 \%$ & $25.9 \%$ & $25.3 \%$ & & \\
\hline & 4 & 279 & 216 & 495 & & \\
\hline & 4 & $18.7 \%$ & $20.1 \%$ & $19.3 \%$ & & \\
\hline & 5 & 104 & 81 & 185 & & \\
\hline & 5 & $7.0 \%$ & $7.5 \%$ & $7.2 \%$ & & \\
\hline
\end{tabular}

No significant relationship was observed between Malocclusion in rural and urban areas.

When oral habits and malocclusion were correlated no statistical significant relationship was observed. $(\mathrm{P}>0.05)$

Table 3

\begin{tabular}{|c|c|c|c|c|c|c|c|c|c|}
\hline & \multicolumn{5}{|c|}{ Malocclusion } & \multirow{2}{*}{ Total } & \multicolumn{2}{|c|}{ Chi square test } \\
\hline & & 1 & 2 & 3 & 4 & 5 & & Chi square value & p-value \\
\hline \multirow{4}{*}{ Thumb sucking } & 0 & 273 & 902 & 614 & 469 & 169 & 2427 & \multirow{4}{*}{3.88} & \multirow{4}{*}{$0.42(\mathrm{NS})$} \\
\hline & $\mathbf{0}$ & $11.2 \%$ & $37.2 \%$ & $25.3 \%$ & $19.3 \%$ & $7.0 \%$ & $100.0 \%$ & & \\
\hline & \multirow{2}{*}{1} & 15 & 49 & 35 & 26 & 16 & 141 & & \\
\hline & & $10.6 \%$ & $34.8 \%$ & $24.8 \%$ & $18.4 \%$ & $11.3 \%$ & $100.0 \%$ & & \\
\hline \multirow{4}{*}{ Tongue thrusting } & 0 & 193 & 649 & 463 & 333 & 116 & 1754 & \multirow{4}{*}{5.91} & \multirow{4}{*}{$0.21(\mathrm{NS})$} \\
\hline & $\mathbf{0}$ & $11.0 \%$ & $37.0 \%$ & $26.4 \%$ & $19.0 \%$ & $6.6 \%$ & $100.0 \%$ & & \\
\hline & \multirow{2}{*}{1} & 95 & 302 & 186 & 162 & 69 & 814 & & \\
\hline & & $11.7 \%$ & $37.1 \%$ & $22.9 \%$ & $19.9 \%$ & $8.5 \%$ & $100.0 \%$ & & \\
\hline & & & & & & & & & \\
\hline
\end{tabular}




\begin{tabular}{|c|c|c|c|c|c|c|c|c|c|}
\hline \multirow{4}{*}{ Mouth breathing } & a & 266 & 888 & 602 & 460 & 165 & 2381 & \multirow{4}{*}{4.11} & \multirow{4}{*}{$0.39(\mathrm{NS})$} \\
\hline & 0 & $11.2 \%$ & $37.3 \%$ & $25.3 \%$ & $19.3 \%$ & $6.9 \%$ & $100.0 \%$ & & \\
\hline & \multirow{2}{*}{1} & 22 & 63 & 47 & 35 & 20 & 187 & & \\
\hline & & $11.8 \%$ & $33.7 \%$ & $25.1 \%$ & $18.7 \%$ & $10.7 \%$ & $100.0 \%$ & & \\
\hline & & & & & & & & & \\
\hline \multirow{4}{*}{ Nail biting } & & 229 & 773 & 518 & 410 & 148 & 2078 & \multirow{4}{*}{2.23} & \multirow{4}{*}{$0.69(\mathrm{NS})$} \\
\hline & $\mathbf{0}$ & $11.0 \%$ & $37.2 \%$ & $24.9 \%$ & $19.7 \%$ & $7.1 \%$ & $100.0 \%$ & & \\
\hline & & 59 & 178 & 131 & 85 & 37 & 490 & & \\
\hline & 1 & $12.0 \%$ & $36.3 \%$ & $26.7 \%$ & $17.3 \%$ & $7.6 \%$ & $100.0 \%$ & & \\
\hline & & & & & & & & \multirow{5}{*}{4.21} & \\
\hline \multirow{4}{*}{ Habits } & 0 & 157 & 532 & 368 & 269 & 90 & 1416 & & \multirow{4}{*}{$0.38(\mathrm{NS})$} \\
\hline & 0 & $11.1 \%$ & $37.6 \%$ & $26.0 \%$ & $19.0 \%$ & $6.4 \%$ & $100.0 \%$ & & \\
\hline & 1 & 131 & 419 & 281 & 226 & 95 & 1152 & & \\
\hline & 1 & $11.4 \%$ & $36.4 \%$ & $24.4 \%$ & $19.6 \%$ & $8.2 \%$ & $100.0 \%$ & & \\
\hline
\end{tabular}

$* \mathrm{p}<0.05$ statistically significant, $\quad \mathrm{p}>0.05$ Non Significant, $\mathrm{N}$

\section{Discussion}

Habits are acquired automatisms, represented by an altered pattern of muscle contraction with complex characteristics, which proceed unconsciously and on a regular basis. ${ }^{23}$ Sucking responses in the early ages are necessary for the survival of the infant and they play an important key role in the early exploration of the child's environment. Psychologists include the development of habits as a part of the normal sequence of maturation in children and recognize that these activities have the potential to become a problem or bad habit, under the circumstances of physical, mental stress, and socio-economic stress. ${ }^{24}$

The present study determined the prevalence of malocclusion, prevalence of habits, co-relation exists between oral habits and malocclusion and co-relation the existence of habits in children going to government and private schools as they could probably belong to different socioeconomic status'. Malocclusion is established close to its full expression in an individual with the eruption of all permanent teeth, thereby young adolescents at the late mixed dentition and early permanent dentition stage provide a much clear prevalence of malocclusion and orthodontic treatment needs than younger children. ${ }^{13}$ In our study prevalence of oral habits was found to be $44.9 \%$. This finding is in agreement with results of Gildasya et $\mathrm{al}^{14}$ which showed $50 \%$ of oral habits in 6-12 years of children, results of Bhayya et $\mathrm{al}^{15}$ showed $38 \%$ of oral habits and results of Quashie-Williams ${ }^{16}$ who found $34.1 \%$ of the children examined presented with an oral habit. In contrast to this observation low prevalence of oral habits $(29.7 \%$ \& $25.5 \%$ ) was reported by Shetty et al., (1998) ${ }^{9}$ and Kharbanda et al., $(2003)^{8}$ who studied prevalence of oral habits in south and north Indian children respectively. Further, Guba et al., ${ }^{17}$ reported that only $3 \%$ of children demonstrated oral habits, which is very much in disagreement with our findings.

Tongue thrusting is the most prevalent oral habit in the present study sample showing $31.7 \%$. which agree the observation of Quashie-Williams., ${ }^{16}$ showing $27 \%$ Gauba et al., ${ }^{17}$ showing $18 \%$, same is supported by the findings of Kharbanda et al., ${ }^{8}$ who reported $18.1 \%$ of children with tongue thrusting habit. However, our findings differed with the findings of Shetty and Munshi $^{9}$ who found a comparatively low prevalence $(3.02 \%)$ of tongue thrust among Mangalore children in the age range of 3-16 years. Findings of Shweta jajoo et al, ${ }^{18}$ differed from our study showing high prevalence of tongue thrusting of $58.8 \%$.

Nail biting was the second most prevalent habit in our study with the incidence rate of $19.1 \%$. This observation is in agreement with the findings of Shetty and Munshi ${ }^{9}$ who reported $12.7 \%$ of children with nail biting, Nidhi Pruthi et $\mathrm{al}^{6}$ showed $12 \%$, This is consistent with the findings of National Oral Health Survey, which reported highest prevalence of "habit of biting nails, lips or objects like pencil" among all habits at both $12(32 \%)$ and 15 -years age $(21 \%)$ in the two regions of Himachal Pradesh. Bhayya et al showed in contrast to the present study showed only $3 \%$ prevalence of nail biting habit.

Recently Baydas B et al., ${ }^{19}$ showed that Enterobacteriaceae were more prevalent in the oral cavities of children with nail-biting habits than in children with no oral habit. This warrants the need for early reorganization of this habit.

Mouth breathing can be related to a variety of causes, including enlarged adenoids, tonsils and nasal concha, obstructive nasal septum displacement, allergic rhinitis, nasal or facial deformities and, more rarely, by foreign bodies $^{22}$. The prevalence of mouth breathing in the present study is $7.3 \%$ Which is in agreement with studies done by Shweta Jajoo $^{18}$ et al which showed $6.3 \%$, Shetty and Munshi $^{9}$ showed $4.6 \%$, Kharbanda et al., ${ }^{8}$ showed $6.6 \%$ and Gildasya et $\mathrm{al}^{14}$ showed $3.26 \%$ prevalence of mouth breathing.

Most of the children are engaged in non-nutritive sucking (NNS) habit associated with hunger, shyness, sleeping, psychological development, fatigue, and development of the face and dorsal structure. ${ }^{20}$ Our study showed the prevalence of thumb sucking of 5.5\% which is in agreement with Shetty and Munshi ${ }^{9}$ showed $3.1 \%$. in contrast to our study other studies have shown higher prevalence of thumb sucking habit i.e. by QuashieWilliams ${ }^{16}$ showed $50 \%$ of thumb sucking habit, Shweta 
Jajoo $^{18}$ showed $31.9 \%$, Gildasya et $\mathrm{al}^{14}$ showed $21.74 \%$. Kharbanda et al., ${ }^{8}$ showed $0.7 \%$ which is very low when compared to the present study.

When comparison was done between socioeconomic status and habits the relation was statistically significant in relation to tongue thrusting habit with $\mathrm{P}$ value- $0.04 *$. This shows that tongue thrusting habit is more prevalent in lower class group in rural area according to Kuppuswamy's socioeconomic scale. This is in disagreement with study done by Calasti et $\mathrm{al}^{1}$ showed that children in higher socioeconomic groups have significantly more oral habits than those of the middle and lower socio-economic groups and the habits are significantly associated with malocclusion.

The prevalence of malocclusion requiring orthodontic treatment is $51.5 \%$ which is in agreement with study done by Nidhi pruthi et $\mathrm{al}^{6}$ showing $52.7 \%$, VanWyk PJ, Drummond $\mathrm{RJ}^{21}$ showed $52.3 \%$ prevalence of malocclusion.

Analysis of prevalence of deleterious oral habits with malocclusion revealed that there is no significant relationship in our study which is in disagreement with studies done by Nidhi Pruthi et $\mathrm{al}^{6}$ showed $28.8 \%$ of oral habits with malocclusion. This is consistent with the findings of Shetty and Munshi ${ }^{9}$ and Sinn J. Minor ${ }^{10}$ who reported $28.95 \%$ and $23 \%$ of malocclusion were caused by habits in their respective studies.

Limitations of the study:

1. The study was limited to schools which represent only the school going children of rural and urban areas; it could be expanded to include non-school going children in its continuation. The present findings are based on a convenience sample and may not represent the general population of children in Bagalkot.

2. Sex may influence the factors analysed here because young women more frequently report more severe oral impacts than men, although this difference reported previously was not statistically significant. Selection bias is likely to have occurred. The sex ratio was skewed; there were more men $(60.3 \%)$ than women $(39.7 \%)$ in this study ${ }^{31,32}$.

3. The patient population was not evenly distributed in regard to socioeconomic level, with $62.9 \%$ reporting a lower upper background. This may have influenced the results.

4. To assess normative orthodontic treatment need, the IOTN-DHC was used. However, the IOTN does not record all aspects of malocclusion, and different indexes may have different thresholds or cut-off points for the consideration of orthodontic treatment need. This can result in a different prevalence of normative orthodontic need because the scoring or grading systems of the orthodontic treatment need indexes reflect the opinion of their developers on the health risks of malocclusion and the potential benefits of orthodontic treatment.

5. Cross-sectional studies have limitations inherent in the design, as such studies are carried out either at a single point in time or over a short period, so the associations identified cannot be considered a causal relationship.

\section{Conclusion}

It was summarized from this study that:

1. The prevalence of malocclusion is high showing $51.1 \%$ and showing no significant difference in rural and urban areas.

2. The prevalence of Oral habits is high showing $44.9 \%$, showing predominantly tongue thrusting and nail biting habits.

3. There is no significant relationship exists between the malocclusion and oral habits.

4. Oral habits when compared in the rural and urban areas it was found that there was significant relationship with tongue thrusting habit. Oral habits are seen more in rural area compared to the urban area as they belong to different socioeconomic status.

Thus, it can be concluded that there is high prevalence of oral habits and malocclusion. All habits are not showing statistically significant relationship except tongue thrusting which is showing statistically significant relationship with more prevalent in rural areas of north Karnataka region of Bagalkot

\section{Source of Funding}

None.

\section{Conflict of Interest}

None.

\section{References}

1. Calasti LJP, Cohen MM, Fales MH. Correlation between malocclusion, oral habits and socio-economical level of preschool children. J Dent 1960;39:450-3.

2. As cited in TM GRABER Orthodontics principles and practice $3^{\text {rd }}$ ed. P.56

3. Yamaguchi, Sueishi. Malocclusion associated with abnormal posture. Bull Tokyo Dent Coll 2003;44:43-54

4. Rashmi G. Chour, Suryakanth Pai, Girish V. Chour, Sangeetha M. Kenchappannavar, Poornima Prameshwarappa. Assessment of various deleterious oral habits and its effects on primary dentition among 3-5 years old children in Davangere city. $J$ Pediatr Dent 2014;2:2

5. Hayder S. Al-Tabi. Prevalence of Bad Oral Habits and relationship with prevalence of malocclusion in sammawa city students aged (6-18) years old. Med J Babylon 2014;11:1

6. Nidhi Pruthi, Girish M. Sogi, Shailee Fotedar. Malocclusion and deleterious oral habits in a north Indian adolescent population: A correlational study. Eur J General Dent 2013;2:3

7. Goto S, Boyd RL, Neilsen L, Iizuka T. Long term follow up of orthodontic treatment of a patient with maxillary protrusion, severe deep overbite and thumb-sucking. Angle Orthod 1994;64(1):7-12.

8. Kharbanda OP, Sidhu SS, Sundaram K, Shukla DK. Oral habits in school going children of Delhi: A prevalence study. $J$ Indian Soc Pedod Prev Dent 2003;21:120-4

9. Shetty SR, Munshi AK. Oral habits in children: A prevalence study. J Indian Soc Pedod Prev Dent 1998;16:61-6. 
10. Sinn JM. Tooth movement in children, 2nd ed. St. Louis: C.V. Mosby Co 1977:243-71.

11. Moyers RE Textbook of Orthodontics $4^{\text {th }}$ ed. P.209-210.

12. Moyers RE Textbook of Orthodontics $4^{\text {th }}$ ed. P.152-154.

13. Proffit WR, Fields HW. Orthodontic treatment planning: From Problem list to specific plan. In Contemporary Orthodontics, Proffit WR. 3rd ed. Elsevier, New Delhi, 2001:196-239.

14. Gildasya, Eriska Riyanti and Syarief Hidayat Prevalence of oral habits in homeless children under care of Yayasan Bahtera Bandung. Dent J (Maj. Ked. Gigi), 2006;39(4):165-167

15. D.P. Bhayya,T.R. Shyagali. Prevalence of Oral Habits in 1113 year-old School Children in Gulbarga city, India Virtual J Orthod 2009;8(3):1-4.

16. R Quashie Williams, O O Dacosta, M C Isiekwe. Prevalence of oral habits among 4-5 year school children on Lagos. Nigerian $J$ Health Biomed Sci 2007;6(1):78-82.

17. Guaba K, Ashima G, Tewari A, Utreja A. Prevalence of malocclusion and abnormal habits in north indian rural children. J Indian Soc Pedod Prev Dent 1998;16(1):26-30.

18. Jajoo S, Chunawala Y, Bijle MN, Shah R, Amol, Gaonkar NK. Oral habits in school going children of Pune: A prevalence study. J Int Oral Health 2015;7(10):1-6.

19. Baydas B, Uslu H, Yavuz I, Ceylan I, Dagsuyu IM. Effect of a chronic nail-biting habit on the oral carriage of Enterobacteriaceae. Oral Microbiol Immunol 2007:22:1-4

20. Peterson JE Jr, Schneider PE. Oral habits. A behavioral approach. Pediatr Clin North Am 1991;38(5):1289-307.

21. VanWyk PJ, Drummond RJ. Orthodontic status and treatment need of 12-year-old children in South Africa using the Dental Aesthetic Index. SADJ 2005;60(8):334-6, 338.

22. Lauterbach W. Situation-response (S-R) questions for identifying the function of problem behaviour: The example of thumb sucking. Br J Clin Psychol 1990;29(Pt 1):51-7.

23. Moyers RE Textbook of Orthodontics $4^{\text {th }}$ ed. P.127-140.

24. Massler M. Oral habits. Origin, evolution and current concept in management. Alpha Omegan 1963;56:127-34.
25. Garde JB, Suryavanshi RK, Jawale BA, Deshmukh V, Dadhe DP, Suryavanshi MK et al. An epidemiological study to know the prevalence of deleterious oral habits among 6 to 12 year old children. J Int Oral Health 2014;6(1):39-43.

26. Shetty RM, Shetty M, Shetty NS, Reddy H, Shetty S, Agrawal A et al. Oral Habits in children of Rajnandgaon, Chhattisgarh, India- A prevalence study. Int J Public Health Dent 2013:4(1):1-7.

27. Sharma S, Bansal A, Asopa K. Prevalence of Oral Habits among Eleven to Thirteen Years Old Children in Jaipur. Int $J$ Clin Pediatr Dent 2015;8(3):208-10.

28. Krishnappa S, Rani MS, Gowda R. Mapping the prevalence of deleterious oral habits among 10-16-year-old children in Karnataka: A cross-sectional study. J Indian Assoc Public Health Dent 2015;13:399-404.

29. Giuseppina Laganà, Caterina Masucci, Francesco Fabi, Patrizio Bollero and Paola Cozza. Prevalence of malocclusions, oral habits and orthodontic treatment need in a 7- to 15-year-old schoolchildren population in Tirana. Progress Orthod 2013;14:12.

30. Mai I. Omer, Amal H. Abuaffan. Prevalence of Oral Habits and its Effect in Primary Dentition among Sudanese Preschool Children in Khartoum City. Indian J Dent Educ 20158(2).

31. Macintyre, S., Ford, G., \& Hunt, K. Do women 'over report' morbidity? Men's and women's responses to structured prompting on a standard question on long standing illness. Soc Sci Med 1982;48:89-98

32. Macintyre, S., Ford, G., \& Hunt, K. Do women 'over report' morbidity? Men's and women's responses to structured prompting on a standard question on long standing illness. Soc Sci Med 1982;48:89-98.

How to cite this article: Redddy $\mathrm{B}$, Gogineni RK, Ganeshkar SV, Rathi KL, Prevalence of deleterious oral habits in school going children in bagalkot region of Karnataka, Indian J Orthod Dentofacial Res 2019;5(3):84-90. 